\title{
CONFLITOS DA SOCIEDADE BRASILEIRA COM AS NORMAS SANITÁRIAS: UM PARALELO ENTRE A REVOLTA DA VACINA E A PANDEMIA DE COVID-19
}

\section{CONFLICTS OF BRAZILIAN SOCIETY WITH SANITARY STANDARTS: A PARALLEL BETWEEN THE VACCINE REVOLT AND THE COVID-19 PANDEMIC}

\author{
Flavio Fernando Batista Moutinho \\ Universidade Federal Fluminense - RJ \\ Centro de Controle de Zoonoses de Niterói - RJ \\ flaviomoutinho@id.uff.br
}

\begin{abstract}
RESUMO
Em épocas de epidemias é comum serem criadas normas sanitárias, baseadas no conceito de polícia médica, para o controle dessas enfermidades. O presente trabalho procurou discutir os conflitos de parcelas da população brasileira com as normas sanitárias tendo como pano de fundo a Revolta da Vacina e a Pandemia de Covid-19. Se na época da Revolta da Vacina a população mais pobre estava revoltada por um acúmulo de coisas como a reforma urbana de Pereira Passos e o processo de gentrificação que a expulsou para longe do centro, sem direito a indenização, a questão moral da exposição do corpo das mulheres aos vacinadores, os abusos da repressão, tudo isso feito de maneira arbitrária, a vacinação obrigatória foi somente um estopim para o acontecimento. $\mathrm{Na}$ pandemia de Covid-19 existe uma complexa situação em que parte da população tem condições de ficar em isolamento social e outra parcela precisa continuar trabalhando, seja por se tratar de atividade essencial, seja por serem trabalhadores informais sem renda fixa. Além disso, uma parcela grande da população reside em aglomerados subnormais em condições insalubres e sub-humanas onde é praticamente impossível manter um isolamento digno, isolar pessoas suspeitas ou doentes e ter acesso à água potável. Por fim, empresários não querem perder seus lucros e insistem que as atividades econômicas não podem ficar paradas, a despeito do risco de aumento do número de mortos.
\end{abstract}

Palavras-chave: Coronavírus. SARS-Cov-2. Polícia Médica.

\begin{abstract}
In times of epidemics, the creation of health standarts are usual, based on the concept of medical police, to control these diseases. The present work sought to discuss the conflicts for parts of the Brazilian population with the sanitary standarts against the background of 1904's Vaccine Upsising and the current Covid-19 Pandemic. In 1904's Vaccine Uprising, the poorest population was revolted by many issues as the urban reform of Pereira Passos and the gentrification process that drove them away from downtown without compensation rights, the moral aspect of exposing women bodies to health agents, the abuses of repression, all done in an arbitrary way, the mandatory vaccination was just a trigger. In current Covid-19 pandemic, there is a complex situation in which part of the population is able to remain in social isolation and another parts need to continue working, either because they work in an essential activity or because they are informal workers without fixed income. In addition, a large part of the population resides in subnormal agglomerations with unsanitary and subhuman conditions where is almost impossible to maintain recommended isolation, isolate suspicious or sick people and access to clean drinking water. Finally, businessmen cannot give up their profits and argue that economics activities must go on, despite the risk of an increasing number of deaths.
\end{abstract}

Keywords: Coronavirus. SARS-Cov-2. Medical Police.

Recebido em: 02/05/2020

Aceito para publicação em: 15/05/2020. 


\section{INTRODUÇÃO}

A Covid-19 é uma doença viral emergente que surgiu em dezembro de 2019 na cidade de Wuhan, na China, transformando-se rapidamente em uma pandemia que vem afetando milhares de vidas mundo a fora, e levando muitas delas ao óbito. Apesar da baixa letalidade, exceto para os chamados grupos de risco, como idosos e cardiopatas por exemplo, sua alta infectividade faz com que o número de óbitos tenha alcançado centenas de milhares em poucos meses (EXÉRCITO BRASILEIRO, 2020).

No intuito de preservar a saúde da população, os países vêm implementando uma série de Intervenções Não Farmacológicas (INF) já que não há vacina ou medicamento para tratar a doença e as pessoas ainda não têm imunidade contra ela (GARCIA; DUARTE, 2020). A base dessas medidas é o isolamento ou distanciamento social para evitar a cadeia de transmissão, evitando que muitas pessoas adoeçam ao mesmo tempo, o que poderia levar ao colapso dos sistemas de saúde, já que nos casos graves muitas vezes há necessidade de internação por longos períodos, podendo não haver leitos hospitalares para atender à demanda.

O Ministério da Saúde vem adotando diretrizes baseado nas recomendações da Organização Mundial da Saúde (OMS) (EXÉRCITO BRASILEIRO, 2020) e estados, Distrito Federal e municípios vêm legislando no sentindo de organizar restrições sanitárias em suas jurisdições e evitar a propagação da enfermidade (OLIVEIRA et al, 2020). Essa situação vem gerando uma série de conflitos, seja de competência político-administrativa, seja por parte de parcela da população que vê seus direitos fundamentais suprimidos e entendem que o país entrará em colapso econômico.

Situações de estranhamento em relação à legislação sanitária e às ações de polícia sanitária por parte do poder público não são uma novidade na história do Brasil e são até entendíveis já que muitas vezes levam a mudanças de costumes e hábitos da população. Ocorre que muitas vezes há uma trama não perceptível à primeira vista por traz dessa revolta de parcela da população, a qual não é exatamente contra a questão sanitária. Isso ficou muito claro na famosa Revolta da Vacina, ocorrida no início do século $X X$, quando Oswaldo Cruz tentou implantar a vacinação obrigatória contra a varíola no Brasil (SEVCENKO, 2010). Este trabalho se propõe a discutir esses conflitos de parcelas da população brasileira com as normas sanitárias tendo como pano de fundo a Revolta da Vacina e a Pandemia de Covid-19.

\section{SÉCULO XX: UM REVOLTA QUE DA VACINA TEVE MAIS O NOME QUE A CAUSA}

O cuidado do Estado com a saúde da população remonta ao século XVIII quando esta passa a ser considerada um bem do Estado importante para a ampliação de seu poder bélico (CARVALHO; BUSS, 2012). O Estado absolutista assumiu a responsabilidade pela saúde dos cidadãos por meio da polícia sanitária e a saúde passou a ser um direito dos cidadãos assegurado pela Revolução Francesa de 1789 e pela Revolução Americana de 1776 (SCLIAR, 2005). O conceito de polícia médica ou sanitária surgiu na Alemanha, em 1779. Seu foco era a questão legal das ações de saúde pública e a intervenção estatal, permitindo que o estado passasse a colher informações sobre a população e ditasse as regras e os modos de vida nas cidades com base em leis e regulamentos (SCLIAR, 2005).

Nas últimas décadas do século XIX, com as transformações advindas da segunda Revolução Industrial e sua revolução tecnológica, são observas as primeiras modificações significativas na saúde pública em terras brasileiras. É uma época em que o país passa por grandes transformações, com a mudança do polo cafeeiro do Vale do Paraíba para o Oeste Paulista levando a um grande aumento de produtividade e incremento da lucratividade. Esse dinamismo do setor cafeeiro levou à atração de outros negócios e de capital, ocasionando investimentos em infraestrutura de transporte, indústrias e à importação de produtos industrializados. Em síntese, essa riqueza gerada pelo café estimulava a urbanização do sudeste brasileiro (ESCOREL; TEIXEIRA, 2012).

O governo federal era responsável somente pela saúde da capital e dos portos, sendo o do Rio de Janeiro um dos principais. Todavia, no início do período republicano as ações de saúde se limitavam praticamente ao combate de epidemias. Os acometidos eram segregados ou no hospital de isolamento do Caju, que fora criado em 1889, ou em enfermarias que eram criadas emergencialmente em períodos de epidemia para tratar os desvalidos. No caso dos navios, os suspeitos ficavam em quarentena e seus tripulantes e passageiros eram encaminhados para os 
lazaretos de Jurujuba, em Niterói, ou da llha Grande, em Angra dos Reis, de maneira compulsória (ESCOREL; TEIXEIRA, 2012).

O Rio de Janeiro era a maior cidade do país, além de centro político, comercial e cultural (ESCOREL; TEIXEIRA, 2012). No final do século XIX e início do século XXI era uma cidade cheia de problemas. Com espaço urbano acanhado, cercado de áreas pantanosas e morros; as condições de vida eram degradantes. Além disso, houve um salto populacional abrupto, com a população passando de 522.651 habitantes em 1890 para 1.157.873 habitantes em 1920 (SEVCENKO, 2010). Além de um porto obsoleto, tinha um sistema viário do período colonial precário, difícil para escoar o café das ferrovias (BUENO, 2005). Esses graves problemas urbanos e a presença das epidemias fazia do Brasil objeto de pressões internacionais que se refletiam como ameaças às classes dominantes e à acumulação de capital, ocasionando o comprometimento do comércio pelo porto do Rio de Janeiro, grande exportador de produtos extrativistas e gêneros alimentícios, bem como grande mercado consumidor (COSTA; ROZENFELD, 2000). Nesse contexto, as epidemias atingiam a cidade periodicamente, principalmente a peste bubônica, a febre amarela e a varíola. Os viajantes de navios estrangeiros sequer se atreviam a descer no porto do Rio de Janeiro (SEVCENKO, 2010) e essa imagem atrapalhava a atração de mão de obra estrangeira para o Brasil, tão necessária após a abolição da escravatura em 1889 (UJVARI,2003).

Foi nesse contexto que Rodrigues Alves assumiu a presidência do Brasil em 1902 e uma de suas principais promessas era sanear o Rio de Janeiro e melhorar o porto da cidade, na época em que a mesma era conhecida como o "túmulo dos estrangeiros" tamanha era a quantidade de pessoas que morriam por causa das epidemias. A cidade era tão temida que as agências de viagem anunciavam como uma vantagem aos passageiros quando os navios faziam viagens diretamente para Buenos Aires sem passar pelo Rio de Janeiro (BUENO, 2005).

Para a reforma da capital Rodrigues Alves nomeou como prefeito Pereira Passos, dando-lhe poderes praticamente ilimitados e imunidade judicial. Assim ele pode tocar seu governo chamado por ele de "regeneração" e pelo povo de "bota-abaixo", inclusive, sem pagar indenização à população afetada (BUENO, 2005). Pamplona (2002) destaca o clima de embriaguez civilizacional que pairava na época da jovem república oligárquica, que desejava implantar boulevards e prédios em estilo neoclássico em substituição à arquitetura irregular colonial existente, a exemplo do que fora feito em cidades como Buenos Aires e Paris.

A lei que previa a reorganização urbana do Rio de Janeiro era, nas palavras de Sevcenko (2010), equivocada, arbitrária e inconstitucional. Ela retirava o direito de defesa da sociedade e dava poderes tirânicos ao prefeito Pereira Passos, como uma lei de exceção. O projeto de modernização de Rodrigues Alves e Pereira Passos teve como primeiro obstáculo a ser extirpado da cidade os cortiços, já que eles além de atrapalharem o trânsito e comprometiam a questão sanitária (BUENO, 2005). Os cortiços eram desocupados e logo demolidos, as áreas alagadiças eram aterradas, o lixo era retirado das ruas (UJVARI, 2003). A reforma de Pereira Passos prejudicou os proprietários dos imóveis que deixaram de ser alugados e os moradores, que foram deslocados para locais mais distantes ou foram obrigados a pagar aluguéis mais caros (SCLIAR, 2005). Mas ela prejudicou sobremaneira os mais pobres (UJVARI, 2003).

Além das obras estruturais, Pereira Passos investiu contra os chamados costumes incivilizados, como o comércio de comida na rua, o costume de cuspir no chão, a exposição de carne nos açougues, os cães soltos nas ruas (PAMPLONA, 2002). Menina dos olhos do projeto de regeneração de Pereira Passos e Rodrigues Alves, a Avenida Central, atual Avenida Rio Branco, foi inaugurada em 1905, e nela os homens só podiam circular de terno e gravata e as mulheres em trajes elegantes (BUENO, 2005). Com a reforma urbana, a população pobre que vivia no centro migrou para as regiões mais desvalorizadas, que eras aquelas de mangues e morros mais afastadas da região central. Nessas áreas foram instalados barracos e casebres em péssimas condições de salubridade e higiene, enquanto o novo centro permanecia sadio e ordeiro (SEVCENKO, 2010).

Para tentar controlar as epidemias foi nomeado o jovem médico Oswaldo Cruz. Ao assumir a Diretoria Geral de Saúde Pública (DGSP), Cruz objetivava erradicar três doenças: febre amarela, peste bubônica e varíola. Para tanto, foi implementada uma reforma da legislação visando eliminar conflitos com a legislação municipal e dando poderes à União para intervir nas cidades por meio de um Código de Posturas. Devido ao seu caráter extremamente duro ele ficou popularmente conhecido como "código de torturas" (BUENO, 2005). 
Para o combate da febre amarela Cruz montou, em 1903, um exército de 85 homens vestidos com uniformes amarelos e portando vasilhas com cresol, que entravam nos imóveis atrás de focos de mosquitos, baseado no trabalho desenvolvido por Finlay em Cuba. Como não havia consenso em relação a essa estratégia, ele foi jocosamente apelidado de "mosqueteiro-mor" e "czar dos mosquitos". Tal ação gerou protestos da população contra a violação de seus lares pelos agentes e processos judiciais, todos negados. A estratégia teve sucesso e já em 1904 não ocorreu epidemia no verão e ocorreram somente 39 óbitos (BUENO, 2005). A lei de 1904 que amparava as ações sanitárias implantavas por Oswaldo Cruz também tinha características arbitrárias. No caso da febre amarela, ela permitia invadir, vistoria, fiscalizar e até demolir casas e construções. Além disso, estabelecia um foro diferenciado para dirimir as questões e vedava recursos à justiça comum (SEVCENKO, 2010). Por isso, o período ficou conhecido como "ditadura sanitária".

Contra a peste bubônica, Cruz além de instituir o processo de desratização da cidade, implantou a figura do "comprador de rato", que comprava por 300 réis cada rato apanhado pela população. A despeito de alguns aproveitadores passarem a criar ratos para vender a ação foi um sucesso e ainda em 1903 a doença encontrava-se controlada. Nem por isso deixou de ser alvo de crítica e deboche por parte da população e da imprensa, que alegava que um rato equivalia ao preço de um quilo de feijão (BUENO, 2005).

O maior desafio se deu em relação à varíola e à implantação da vacinação obrigatória. Além do fato da vacina ser obrigatória, é importante destacar que a lei dava direito aos vacinadores entrarem a força nas residências das pessoas para vaciná-las e, em caso de recusa, leva-las presas. Além disso, no imaginário popular, a vacina poderia causar a doença, os médicos nada sabiam sobre a varíola e havia, inclusive, quem acreditasse que a vacina era feita a partir do sangue dos ratos que eram comprados pelo governo ou que ela deixasse os vacinados com aspecto de vaca, por ser produzida com substâncias extraídas desses animais. Outro fator importante era de aspecto moral já que os homens não aceitavam que suas esposas ou filhas mostrassem braços, coxas ou colos a outros homens para serem vacinadas (BUENO, 2005).

A lei que tornava a vacina obrigatória foi aprovada em outubro, passando então à fase de regulamentação. Mas esta fase era feita diretamente pela Diretoria Geral de Saúde Pública, sem interferência do Poder Legislativo, o que causou muito desconforto. Além disso, essa regulamentação foi considerada muito rígida, contemplando de recém nascidos a idosos, prevendo pesadas multas, demissões, limitando recursos e defesas por parte dos cidadãos (SEVCENKO, 2010), exigindo atestado de vacina para casamentos e viagens (ESCOREL; TEIXEIRA, 2012).

A regulamentação foi publicada no dia nove de novembro e no dia seguinte as agitações começaram (SEVCENKO, 2010). A população se revoltou, teve início um quebra-quebra generalizado; bondes foram virados e incendiados, equipamentos públicos foram quebrados, um breve levante militar ocorreu nas escola da Praia Vermelha (SEVCENKO, 2010; ESCOREL; TEIXEIRA, 2012). O objetivo de Oswaldo Cruz era desenvolver uma campanha fulminante, rápida, maciça, sem qualquer tipo de embaraço. Todavia ela exigiria amplo sucesso em um curto prazo, com submissão incondicional. Essa situação, segundo Sevcenko (2010), de "insensibilidade tecnocrática e política, foi fatal para a lei da vacina".

Setores políticos de oposição, envolvendo monarquistas depostos pelo novo regime e jovens oficiais positivistas, se aproveitaram da indignação da população que vinha sendo atiçada pelo movimento positivista (apostolado positivista) e pelos sindicalistas para articular um golpe de estado (UJVARI, 2003; SEVCENKO, 2010). Houve uma rápida resposta da população mais pobre ao apelo moral incentivado pela Liga Contra a Vacina Obrigatória, fundada em 1904 e presidida pelo militar Lauro Sodré (UJVARI, 2003; PAMPLONA, 2012). Oswaldo Cruz ainda teve que lutar contra o próprio conhecimento médico da época. A faculdade de medicina, por exemplo, defendia que a luta contra a febre amarela deveria focar na desinfecção do solo para matar as supostas bactérias causadoras da doença. Já os positivistas consideravam a vacinação obrigatória um atentado contra a liberdade individual. Para se conseguir emprego era exigido o comprovante de vacinação e este era cobrado quando fornecido por médicos particulares, o que encontrava resistência do movimento sindicalista (SCLIAR, 2005).

A revolta não pode ser creditada somente à obrigatoriedade da vacinação em si. Esses outros fatores muito relevantes têm que ser considerados nesse contexto. Até porque a vacina já era obrigatória para toda a população desde o período imperial (1844) e com o advento da república renovou-se a 
obrigatoriedade para crianças acima de seis meses de idade, e sucessivamente até 1903 diversos decretos foram aumentando o alcance da vacinação, envolvendo militares, funcionares públicos, escolas públicas, prisioneiros, menores abandonados. A questão é que essa obrigatoriedade não era cobrada (PAMPLONA, 2002).

Foi necessário forte aparato militar e alguns dias para controlar a revolta. Não se sabe ao certo quantas pessoas morreram ou foram presas e deportadas, mas foram muitas. Dia 16 de novembro Rodrigues Alves revogou a lei da vacinação obrigatória (SEVCENKO, 2010). "A revolta não visava o poder, não pretendia vencer, não podia ganhar nada. Era somente um grito, uma convulsão de dor, uma vertigem de horror e indignação" (SEVCENKO, 2010, p.93).

Em 1908, com parte da população não imunizada, houve uma nova epidemia de varíola no Rio de Janeiro, com nove mil casos e uma morte em cada cem mil habitantes (UJVARI, 2003). Após sua experiência nas campanhas de saúde pública, Oswaldo Cruz passou a dedicar-se somente à pesquisa no instituto de Manguinhos, atual Fundação Oswaldo Cruz, que ele havia criado no bairro do mesmo nome, na cidade do Rio de Janeiro (SCLIAR, 2002).

A retórica republicana dos revoltosos nesse "Brumário de 1904" reagiu, em especial, aos abusos da repressão diária. Era a demonstração de que os pobres urbanos também sabiam que as leis vigentes tinham dois pesos e duas medidas e que a violência do cotidiano pouco diferia daquela experimentada durante o império (PAMPLONA, 2002, p. 83).

\section{SÉCULO XXI: COVID-19, TODOS NO MESMO BARCO OU TODOS NO MESMO OCEANO COM BARCOS DIFERENTES E ALGUNS ATÉ SEM BARCO?}

A pandemia de Covid-19 teve início na cidade de Wuhan, na China em dezembro de 2019. Devido à sua rápida propagação em 30 de janeiro de 2020 a OMS classificou-a como Emergência de Saúde Pública de Importância Internacional (EXÉRCITO BRASILEIRO, 2020). O governo federal agiu prontamente, publicando o decreto $n^{\circ} 10.211$ reativando o Grupo Executivo Interministerial de Emergência em Saúde Pública de Importância Nacional e Internacional e abrindo licitação para alocação de mil leitos adicionais em hospitais de referência indicados pelos estados para casos da doença, já em 30 de janeiro de 2020 (CRODA; GARCIA, 2020). Já no dia 04 de fevereiro o governo brasileiro declarou Emergência de Saúde Pública no país (EXÉRCITO BRASILEIRO, 2020). Ainda em fevereiro, foi promulgada a lei 13.979 para regulamentar o enfrentamento da pandemia, prevendo as estratégias de isolamento, quarentena, restrição de locomoção, fechamento de fronteiras internacionais, realização compulsória de exames, testes de laboratório, coleta de material biológico, requisição de bens, dentre outras medidas (BRASIL, 2020a).

Por recomendação da OMS, o Ministério da Saúde passou a recomendar Intervenções Não Farmacológicas para evitar que um grande número de pessoas adoecessem simultaneamente, levando ao colapso dos sistemas de saúde público e privado brasileiros. Essas estratégias envolveriam, principalmente o incentivo ao trabalho domiciliar, a etiqueta respiratória, a lavagem das mãos e o distanciamento ou isolamento social ampliado (BRASIL, 2020b). Como já foi dito, estados, o Distrito Federal e municípios passaram a legislar por decretos, ampliando essas estratégias, obrigando ao fechamento de atividades comerciais e de serviços não essenciais, fechamento de unidades escolares, paralisação de linhas de transportes, dentre outras ações (OLIVEIRA et al, 2020).

Essa situação da criação de legislações subnacionais levou a um conflito de prefeitos e governadores com o governo federal e a discussão chegou ao Poder Judiciário. O país passa hoje por um conflito de coordenação territorial e o pacto federativo se mostra muito centralizado na figura da União e, ao mesmo tempo, nebuloso na definição de competências. Simultaneamente assiste-se a um processo de politização da saúde pública antecipando-se de certa maneira um processo eleitoral. Tal situação levou o Supremo Tribunal Federal a decidir que estados e municípios têm autonomia para determinar medidas de isolamento social em sua jurisdição. A concentração de recursos na União dificulta a ação autônoma dos estados e municípios no combate da pandemia e, ao mesmo tempo, o governo federal não se mostra proativo no sentido de unificar os princípios norteadores das ações em escalas subnacionais e, pior, mostra incongruência de discursos e ações (RODRIGUES; AZEVEDO, 2020). 
De fato, a OMS, visando interromper as cadeias de transmissão e retardar a transmissão da Covid19, recomendou o distanciamento físico e social, garantindo a distância de ao menos um metro entre as pessoas, incentivou o trabalho domiciliar, o ensino a distância, a prevenção de aglomerações, o fechamento de serviços não essenciais, a proteção de grupos vulneráveis, a restrição de deslocamentos, associados à medidas individuais, como a etiqueta da tosse e a lavagem periódica das mãos (WHO, 2020).

Obviamente que nem todas as profissões e pessoas poderiam simplesmente parar de trabalhar e praticar o isolamento domiciliar. Serviços essenciais precisariam continuar a ser prestados, comércios de produtos essenciais precisariam continuar a funcionar, ou seja, alguns grupos de pessoas continuariam mais expostos ao risco que outros grupos de pessoas. Mas é fundamental destacar que, ao optarmos por ficar em casa, estamos protegendo aqueles que não têm essa opção, por diminuir o risco de transmissão (BADIOUP, 2020). Harvey (2020) chama a atenção para o inconveniente mito de que as doenças infecciosas seriam democráticas e não reconheceriam classes, barreiras ou limites sociais. Nesse quesito ele destaca que a força de trabalho que está mais exposta à doença nessa pandemia, excetuando-se obviamente os profissionais de saúde, seria a nova classe trabalhadora que se não correr o risco de adoecer, corre o risco de ser demitida ou ficar sem renda. São trabalhadores de aeroportos, do setor de logística, de supermercados, dentre outros.

Outra questão que precisa ser considerada são as diferenças socioeconômicas existentes no país. A situação sanitária nos bairros mais pauperizados, onde mora a maior parte da população urbana muitas vezes é um fator limitante ou mesmo impeditivo para o isolamento social, estratégia essa tão importante nesse período pandêmico. Muitas vezes em uma casa mora mais de uma família. Não há cômodos vazios para isolar possíveis doentes, às vezes sequer há água encanada para a lavagem das mãos (MACEDO et al, 2020). Assim, como nas palavras de Souza Neto e Castro (2020), a vulnerabilidade ao vírus e à Covid-19 são "marcados geograficamente". Então, a Covid-19 ao se instalar nas áreas mais pobres, onde falta água para lavar as mãos e onde as pessoas têm que se arriscar e descumprir o isolamento social para conseguir alguma renda, tende a alcançar morbidade e mortalidade bem maiores, tornando fundamental um programa de ajuda financeira do poder público e as campanhas de divulgação de como prevenir a doença (FARIAS, 2020).

Motoristas de ônibus, de vans, entregadores em suas bicicletas e motocicletas, vendedores em trens. Não é possível coloca-los em casa em isolamento com seus vínculos precarizados de trabalho. Essas pessoas de modo geral residem em favelas sem saneamento e equipamentos de saúde adequados e algumas com doenças preexistentes agravantes, como asma, bronquite e tuberculose, comuns nas condições socioambientais de suas residências (BARBOSA, 2020).

Importante destacar, que o isolamento domiciliar repercute na renda dos trabalhadores informais e impactará os assalariados com demissões ou diminuição dos rendimentos por diminuição da jornada de trabalho (OLIVEIRA et al, 2020). Para Carvalho et al (2020) a base da pirâmide de renda brasileira é mais vulnerável à crise de saúde pública causada pela pandemia de Covid-19 então, além da ampliação do número de leitos disponíveis no SUS os autores defendem a implementação de políticas de preservação da renda que permitam a essas pessoas manterem o isolamento social. $O$ Congresso Nacional aprovou uma política de transferência de renda com auxílio emergencial que varia de $R \$ 600,00$ a $R \$ 1.200,00$ para pessoas de baixa renda que vivam em condição de vulnerabilidade social, em sua maioria trabalhadores informais (MACEDO et al, 2020).

Mas o ineditismo da situação de confinamento ou isolamento social para evitar o colapso social e resguardar vidas humanas vai levar a um inevitável colapso econômico, que demandará medidas de apoio dos governos a segmentos econômicos, no que pode ser considerado um teste para a economia global (EXÉRCITO BRASILEIRO, 2020). Está sendo discutida, inclusive, a necessidade de um plano global de reestruturação e recuperação econômica, supervisionado e gestado por autoridade intergovernamental (UEBEL, 2020).

A Alemanha, por exemplo, vai investir 750 bilhões de euros (ROXO, 2020), o Reino Unido vai cobrir até $80 \%$ do salário dos seus trabalhadores e até $80 \%$ dos rendimentos dos autônomos (ROXO, 2020). Mas o pacote de apoio econômico brasileiro é tímido e tardio, visando reforçar as empresas e apoiar trabalhadores. Ainda que ajude possíveis dificuldades de caixa e na manutenção de alguns empregos, é insuficiente para manter a economia aquecida durante o isolamento social e seu consequente lockdown econômico. Tal situação tem robusto potencial para gerar recessão, a 
depender do tempo que perdurarem as estratégias de controle da pandemia (MARANHÃO; SENHORAS, 2020).

A preponderância do papel do estado nesse contexto de fragilidade econômica que se desenha é visível, como indutor e protagonista do processo de recuperação econômica que se avizinha. No curto prazo, programas de transferência de renda como Bolsa família e auxílios emergenciais a agricultores familiares e microempreendedores, que englobam grandes parcelas da população, possibilitam reduzir possíveis pressões sociais (EXÉRCITO BRASILEIRO, 2020).

Um fato vem chamando muita atenção durante todo esse tempo de pandemia, é a ocorrência de um processo simultâneo de negação de fatos históricos e evidências científicas ao mesmo tempo que prioriza-se a mitigação de efeitos econômicos em detrimento do isolamento social. Nesse contexto, cientistas em diversas partes do mundo têm que lutar com os desafios da própria doença e contra a desinformação já que diversos governos elegeram como inimigos a imprensa, o conhecimento, a política e a ciência, bases das democracias liberais do Estado Moderno. Percebe-se que o poder e controle desses governos vêm exatamente dessa mistura de negacionismo com obscurantismo religioso, teorias da conspiração e negação de fatos históricos, associados ao uso das redes sociais e seus algoritmos. Os países que fugiram a essa visão turva, confiaram no conhecimento científico e reconheceram a gravidade da situação, tomando decisões estratégicas a partir dessas informações, têm tido mais sucesso no controle da pandemia e na redução do número de mortos (TROI; QUINTILIO, 2020). Certamente, grupos sociais pouco permeáveis ao discurso científico reagirão de maneira diferente de grupos sociais mais permeáveis a esse discurso em situações de epidemias (CARRARA, 2020).

De acordo com Morel (2020), no Brasil vem ocorrendo o crescimento do discurso negacionista em relação à gravidade da doença e à importância dos cuidados para combatê-la. Inclusive esse discurso é recorrentemente reproduzido pelo presidente da república. Esse argumento busca individualizar o cuidado, responsabilizando as famílias pelo cuidado com as pessoas do grupo de risco, tirando a responsabilidade coletiva em relação aos cuidados com as pessoas mais vulneráveis. A própria mídia brasileira reproduz conteúdos com informações que levam desconfiança em relação à ciência (BERTOLLI FILHO, 2012). Tais discursos negacionistas tornam fundamental a fala de Scliar sobre a figura do sanitarista, cujas

\begin{abstract}
medidas são apoiadas pela ciência, porque é dela que nasce a autoridade do sanitarista. Sua verdade é a verdade científica. Daí o desprezo que ele sente pela retórica do político, sobretudo o pequeno político, o político de clientela, com suas manobras, suas tergiversações, suas meias-verdades e meias-mentiras, sua dissimulação (SCLIAR, 2005, p. 118-119).
\end{abstract}

Alguns empresários brasileiros vêm apoiando uma campanha que pode levar a um aumento exponencial do número de mortes, alegando que pode até faltar comida se a economia não voltar a funcionar. A campanha, intitulada "O Brasil não pode parar", foi lançada pelo governo federal e contraria o que é preconizado por cientistas e pelo próprio Ministério da Saúde. Apesar de interrompida oficialmente pelo poder judiciário, segue ocorrendo paralelamente nas redes sociais, defendendo que o que importa é salvar a economia, ainda que vidas sejam perdidas, porque a perda de vidas é inevitável. Trata-se de um fundamentalismo econômico que tem a economia como centro em detrimento das vidas humanas (FRIGOTTO, 2020). As redes sociais são um território livre para rumores descontrolados, informações falsas e obscuras (BADIOUP, 2020).

Diversas carreatas vêm sendo feitas para apoiar a abertura das empresas Brasil a fora. Nesse contexto, percebe-se que parte da classe dominante vem relegando a vida imediata da classe trabalhadora mais pobre na sanha de defender seus lucros imediatos, o que mostra que esta classe é fundamental para gerar os lucros dessa classe dominante, que pode se manter em isolamento mas quer que seus funcionários se exponham ao risco em nome da economia (SOUZA NETO; CASTRO, 2020). Os discursos do presidente que criam uma falsa dicotomia entre saúde e economia, difundida principalmente através de fake news, camuflam relações de poder existentes entre lobbies empresariais e o Estado brasileiro (MACEDO et al, 2020, p. 3).

Para Macedo (2020), as declarações do presidente da república vão na contramão das medidas de combate defendidas pelo Ministério da Saúde e a OMS, criando um ambiente político que legitima a flexibilização dos decretos municipais que visam ao isolamento social (MACEDO et al, 2020). 
Esses discursos se assemelham, de certa maneira, ao de Artur Neiva, então diretor do Serviço Sanitário Estadual de São Paulo, na época da pandemia de Gripe Espanhola, que 15 dias antes da doença chegar à capital convocou a imprensa para informar que os serviços de saúde estariam preparados para enfrentar o problema, que não haveria interferência na normalidade da cidade e a doença não causaria maiores danos à população. Quinze dias depois ele voltava a público para dizer que os hospitais pouco ou nada podia fazer para socorrer os doentes ou proteger os sadios e que a população deveria lutar por conta própria contra a doença. Ele mesmo acabou adoecendo e diversos médicos abandonaram a cidade na época com medo de se infectarem (BERTOLLI FILHO, 2012)

Outros exemplos de descumprimento das normas sanitárias criadas visando ao controle da Covid-19 são os deslocamentos para as cidades turísticas nos feriados prolongados (Figura 1), as visitas às praias (Figura 2) e a abertura de comércios não essenciais (Figura 3).

Figura 1 - Manchete noticiando o engarrafamento no acesso à cidade praiana de Búzios em pleno período de distanciamento social no estado do Rio de Janeiro

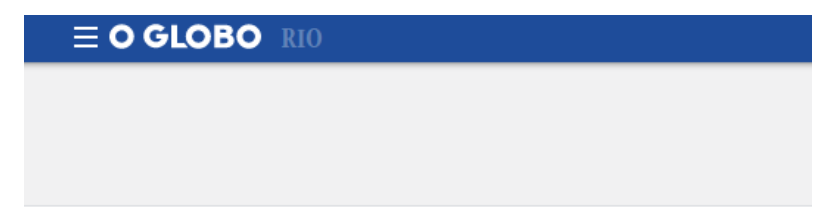

\section{Com previsão de sol, Búzios registra engarrafamento para entrar na cidade nesta quinta, véspera de feriado}

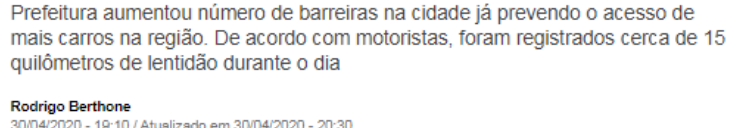

Fonte: O Globo (2020).

Figura 2 - Manchete noticiando a ida dos cariocas à praia apesar da proibição legal de aglomerações no estado do Rio de Janeiro

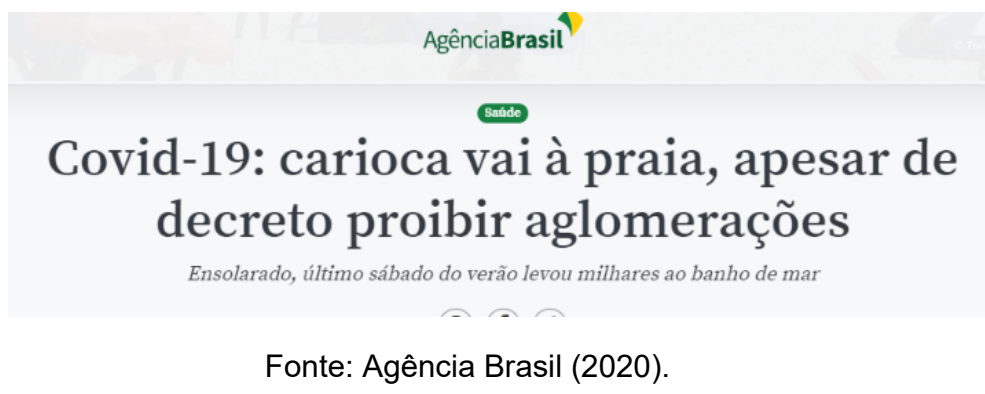


Figura 3 - Manchete noticiando a autuação de loja por desobediência à legislação que obrigava o fechamento em função da pandemia de Covid-19 na Paraíba

G PARAÍBA

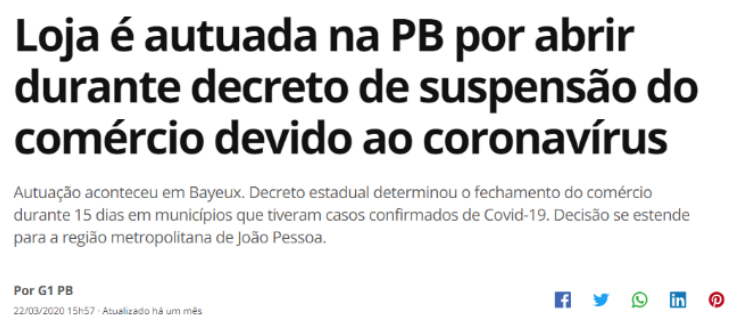

Fonte: G1 (2020).

Após um primeiro momento em que houve redução da circulação das pessoas nos grandes centros urbanos, estudos mais recentes mostram tendência de aumento de circulação em cidades como Rio de Janeiro, São Paulo e Porto Alegre (RS) (FIOCRUZ, 2020). Deve-se tomar muito cuidado na determinação do início e da duração das INF já que, com o passar do tempo pode ocorrer "fadiga de intervenção", que leva à perda de adesão por uma parte da população devido ao longo tempo de exposição àquela situação (QUALLS et al, 2020), mas não se pode negligenciar o poder dessas informações contraditórias por parte do poder público e das redes sociais sobre as pessoas.

Apesar disso, pesquisa de opinião recentemente divulgada mostrou que $76 \%$ da população era favorável ao isolamento domiciliar ainda que isso prejudique a economia e cause desemprego. Além disso, $65 \%$ era favorável à manutenção do fechamento do comércio de produtos não essenciais. Já o isolamento vertical (somente para pessoas do grupo de risco), tinha maior apoio entre os empresários, 49\% (DATAFOLHA, 2020).

\title{
CONSIDERAÇÕES FINAIS
}

Considerando o exposto nos dois episódios históricos, o vivido no início do século XX e o que estamos vivenciando atualmente, fica claro que muito dos conflitos que existem em relação ao cumprimento das normas sanitárias em momento de epidemias vêm muitas vezes de situações mais complexas do que a própria norma em si. Fatores como contexto histórico, moral, disputas políticas, ideologia, economia, tudo isso deve ser considerado para se entender o porquê de haver esse estranhamento e descumprimento dessas normas. Para Carvalho e Buss (2012) no desenvolvimento da saúde pública sempre estiveram associadas historicamente relações de influência recíproca entre estruturas sociais e políticas, saúde e economia.

De acordo com Minayo (2009, p. 191)

\begin{abstract}
introduzindo o tema da cultura na interpretação das estruturas, da sociedade e, também, do tema da saúde e da doença, a antropologia demarca um espaçamento radical, na medida em que o fenômeno cultural não é apenas um lugar subjetivo. Ele possui uma objetividade que tem a espessura da vida, por onde passa o econômico, o político, o religioso, o simbólico e o imaginário. Ele é também o locus onde se articulam conflitos e concessões, tradições e mudanças e onde tudo ganha sentido, ou sentidos, uma vez que nunca há humano sem significado assim como nunca existe apenas uma explicação para determinado fenômeno.
\end{abstract}

Se na época da Revolta da Vacina a população mais pobre estava revoltada por uma acúmulo de situações como a reforma urbana de Pereira Passos e o processo de gentrificação que a expulsou para longe do centro, sem direito a indenização, a questão moral da exposição do corpo das mulheres aos vacinadores, os abusos da repressão e tudo isso feito de maneira arbitrária sem um 
processo de sensibilização ou diálogo, a vacinação obrigatória foi somente um estopim, a gota d'água para o acontecimento.

Agora na pandemia de Covid-19, em que as normas criadas no Brasil nem são tão drásticas se compararmos, por exemplo, com as Filipinas, onde quem desobedecer a quarentena pode ser alvejado e morto pela polícia (UEBEL, 2020), existe toda uma complexa situação em que parte da população tem condições de ficar em isolamento social e outra parcela precisa continuar trabalhando, seja por se tratar de atividade essencial, seja por ser trabalhador informal sem renda fixa. Além disso, uma parcela grande da população reside em aglomerados subnormais em condições insalubres e sub-humanas onde é praticamente impossível manter um isolamento digno, isolar pessoas suspeitas ou doentes e, mesmo, ter acesso à água potável para lavar as mãos. Por fim, alguns empresários não querem perder seus lucros e insistem que as atividades econômicas não podem ficar paradas, a despeito do risco de aumento do número de mortos.

O que se pode perceber nisso tudo é que, passados mais de cem anos, as desigualdades sociais ainda se mostram como fatores determinantes no processo saúde-adoecimento na sociedade brasileira, sendo que as elites têm melhores condições de se proteger das doenças infecciosas do que as classes menos abastadas, que acabam mais expostas ao risco de adoecer e, consequentemente, morrer.

\section{REFERÊNCIAS}

AGÊNCIA BRASIL. Saúde. 03/2020. Covid-19: carioca vai a praia apesar de decreto proibir aglomerações. Disponível em: https://agenciabrasil.ebc.com.br/saude/noticia/2020-03/covid-19carioca-vai-praia-apesar-de-decreto-proibir-aglomeracoes. Acesso em: 01 mai 2020.

BADIOUP, A. Sobre a situação epidêmica. In: DAVIS, M. et al: Coronavírus e a luta de classes. Terra sem Amos: Brasil, 2020. p. 35-42.

BARBOSA, J. L. Por uma quarentena de direitos para as favelas e as periferias! Espaço e Economia, v. 9, n. 17, 2020. Disponível em: Acesso em: 24 abr 2020. https://doi.org/10.4000/espacoeconomia.10274

BERTOLLI FILHO, C. Novas doenças, velhos medos: a mídia e as projeções de um futuro apocalíptico. In: MONTEIRO, Y. N.; CARNEIRO, M. L. T. (Org.). As doenças e os medos sociais. São Paulo: Fap-Unifesp, 2012. p. 13-34

BRASIL. Ministério da Saúde. Boletim Epidemiológico 07. Especial: Doença pelo Coronavírus 2019. 2020 b. Disponível em: https://www.saude.gov.br/images/pdf/2020/April/06/2020-04-06---BE7--Boletim-Especial-do-COE---Atualizacao-da-Avaliacao-de-Risco.pdf. Acesso em: 20 abr 2020.

BUENO, E. À sua saúde. A Vigilância Sanitária na História do Brasil. Brasília: Anvisa, 2005.

CARRARA, S. As Ciências Sociais e a Saúde Coletiva frente a atual epidemia de ignorância, irresponsabilidade e má-fé. Boletim Especial Cientistas Sociais e o coronavírus, n. 3, 2020. Disponível em: http://www.anpocs.com/index.php/ciencias-sociais/destaques/2309-boletim-n-3-asciencias-sociais-e-a-saude-coletiva-frente-a-atual-epidemia-de-ignorancia-irresponsabilidade-e-ma-fe. Acesso em: 25 abr 2020.

CARVALHO, A. I.; BUSS, P. M. Determinantes sociais na saúde, na doença e na intervenção. In: GIOVANELLA, L. et al (Org.). Políticas e Sistema de Saúde no Brasil. 2 ed. Rio de Janeiro: Fiocruz, 2012. p. 121-142.

CARVALHO, L.; NASSIF PIRES, L.; LIMA XAVIER, L. COVID-19 e Desigualdade no Brasil. 2020. Disponível em: http://cebes.org.br/2020/04/covid-19-e-desigualdade-no-brasil/. Acesso em: $24 \mathrm{abr}$ 2020.

COSTA, E. A.; ROZENFELD, S. Constituição da Vigilância sanitária no Brasil. In: ROZENFIEL, S. (Org.) Fundamentos da Vigilância Sanitária. Rio de Janeiro: Fiocruz: 2000. p. 15-40. https://doi.org/10.7476/9788575413258

CRODA, J. H. R.; GARCIA, L.P. Resposta imediata da Vigilância em Saúde à epidemia da COVID-19. Epidemiologia e serviços de saúde, v. 29, n. 1, e2020002, 2020. https://doi.org/10.5123/S1679$\underline{49742020000100021}$

DOI:http://dx.doi.org/10.14393/Hygeia0054379 $\quad$ Hygeia $\quad$ Edição Especial: Covid-19, Jun./2020 $\quad$ p.60 - 71, $\quad$ pág. 69


DATAFOLHA. Opinião sobre a pandemia coronavírus: comportamento da população e medidas do governo. $2020 . \quad$ Disponível em: http://media.folha.uol.com.br/datafolha/2020/04/06/6c9855d692b869f13c5d83c421568342hb.pdf. Acesso em: 01 mai 2020.

ESCOREL, S.; TEIXEIRA, L. A. História das Políticas de Saúde no Brasil e 1822 a 1963: do Império ao desenvolvimento populista. In: GIOVANELLA, L. et al (Org.). Políticas e Sistema de Saúde no Brasil. 2 ed. Rio de Janeiro: Fiocruz, 2012. p. 279-321.

EXÉRCITO BRASILEIRO. Centro de Estudos Estratégicos. Crise Covid-19: estratégias de transição para a normalidade. Disponível em: http://index.php/ultimas-noticias/599-crise-covid-19estrategias-de-transicao-para-a-normalidade. Acesso em: 02 abr 2020.

FARIAS, H. S. O avanço da Covid-19 e o isolamento social como estratégia para redução da vulnerabilidade. Espaço e Economia, v. 9, n. 17, 2020. Disponível em: Acesso em: 24 abr 2020. https://doi.org/10.4000/espacoeconomia.11357

FIOCRUZ - Fundação Oswaldo Cruz. MonitoraCovid-19: alerta para aumento de circulação nas ruas. Disponível em: www.ensp.fiocruz.br/portal-ensp/informe/site/materia/detalhe/48639. Acesso em: 01 mai 2020.

FRIGOTTO, G. Empresários mais ricos do Brasil: a ignorância, o cinismo e a ganância que matam. Espaço e Economia, v. 9, n. 17, 2020. Disponível em: http://journals.openedition.org/espacoeconomia/10852. Acesso em: 24 abr 2020. https://doi.org/10.4000/espacoeconomia.10852

GARCIA, L. P.; DUARTE, E. Intervenções não farmacológicas para o enfrentamento à epidemia da COVID-19 no Brasil. Epidemiologia e Serviços de Saúde, v. 29, n. 2, e2020222, 2020.

G1. Paraíba. Loja é autuada na PB por abrir durante decreto de suspensão do comércio deviso ao coronavírus. Disponível em: https://g1.globo.com/pb/paraiba/noticia/2020/03/22/loja-e-autuada-na-pbpor-abrir-durante-decreto-de-suspensao-do-comercio-devido-ao-coronavirus.ghtml. Acesso em: 01 mai 2020.

HARVEY, D. Política anticapitalista em tempos de Covid-19. In: DAVIS, M. et al: Coronavírus e a luta de classes. Terra sem Amos: Brasil, 2020. p. 13-23.

MACEDO, Y. M.; ORNELLAS, J. M.; BOMFIM, H. F. Covid-19 nas favelas e periferias brasileiras. Boletim de Conjuntura, v. 2, n. 4, p.50-54, 2020.

MARANHÃO, R. A.; SENHORAS, E. M. Pacote econômico governamental e o papel do BNDES na guerra contra o novo coronavírus. Boletim de Conjuntura, v. 2, n. 4, p.27-39, 2020.

MINAYO, M. C. S. Contribuições da antropologia para pensar e fazer saúde. In: CAMPOS, G. W. S. et al (Org.). Tratado de Saúde Coletiva. São Paulo: Hucitec; Rio de Janeirio: Fiocruz, 2009. p. 189218.

MOREL, A. P. M. Da educação sanitária a educação popular em saúde: reflexões sobre a pandemia do coronavírus. Revista estudos libertários, v. 2, n. 3, 2020. Disponível em: https://revistas.ufrj.br/index.php/estudoslibertarios/article/view/34114/19178. Acesso em: 25 abr 2020.

O GLOBO. Rio. Com previsão de sol Búzios registra engarrafamento para entrar na cidade nesta quinta véspera de feriado. 30/04/2020. Disponível em: https://oglobo.globo.com/rio/comprevisao-de-sol-buzios-registra-engarrafamento-para-entrar-na-cidade-nesta-quinta-vespera-deferiado-1-24404171. Acesso em: 01 mai 2020.

OLIVEIRA, T. C.; ABRANCHES, M. V.; LANA, R. M. (In)Segurança alimentar no contexto da pandemia por SARS-CoV-2. Cadernos de Saúde Pública, v. 36, n. 4:e00055220, 2020. https://doi.org/10.1590/0102-311x00055220

PAMPLONA, M. A. A revolta era da vacina? In: SCLIAR, M. et al (Org.). Saúde Pública: histórias, políticas e revolta. São Paulo: Scipione, 2002. p. 65-87. 
QUALLS, N.; LEVITT, A.; KANADE, N. et al. Community mitigation guidelines to prevent pandemic influenza - United States, MMWR Recommendations and Reports, v. 66, n. 1, p. 1-32, 2017. https://doi.org/10.15585/mmwr.rr6601a1

RODRIGUES, J. N.; AZEVEDO, D. A. Pandemia do Coronavírus e (des)coordenação federativa: evidências de um conflito políticoterritorial. Espaço e Economia, v. 9, n. 18, 2020. Disponível em: http://journals.openedition.org/espacoeconomia/12282. Acesso em: 24 abr 2020. https://doi.org/10.4000/espacoeconomia.12282

ROXO, R. Biopolítica, guerra híbrida e reestruturação do capitalismo: a globalização como ela é. Espaço e Economia, v. 9, n. 18, 2020. Disponível em: http://journals.openedition.org/espacoeconomia/13376. Acesso em: 24 abr 2020. https://doi.org/10.4000/espacoeconomia.13376

SCLIAR, M. Políticas de Saúde Pública no Brasil: uma visão Histórica. In: SCLIAR, M. et al (Org.). Saúde Pública: histórias, políticas e revolta. São Paulo: Scipione, 2002. p. 45-63.

SCLIAR, M. Do mágico ao social: trajetória da saúde pública. São Paulo: Senac São Paulo, 2005.

SEVCENKO, N. A Revolta da Vacina: mentes insanas em corpos rebeldes. Rio de Janeiro: Cosac Naify, 2010.

SOUZA NETO, J. A.; CASTRO, F. M. Capitalism über alles: uma interpretação da pandemia de coronavírus no Brasil à luz da geografia radical de Neil Smith. Espaço e Economia, v. 9, n. 18, 2020. Disponível em: http://journals.openedition.org/espacoeconomia/12104. Acesso em: 24 abr 2020. https://doi.org/10.4000/espacoeconomia.12104

TROI, M.; QUINTILO, W. Coronavirus: licoes anti-negacionistas e o futuro do planeta. SciELO em Perspectiva. Disponível em: https://blog.scielo.org/blog/2020/03/31/coronavirus-licoes-antinegacionistas-e-o-futuro-do-planeta/\#.XqnjHZ5KjIU. Acesso em: 25 abr 2020.

UEBEL, R. R. G. A geopolítica do coronavírus em tempos de incertezas. Diálogos internacionais, v. 7, n. 70, 2020.

UJVARI, S. C. A história e suas epidemias: a convivência do homem com os microrganismos. Rio de Janeiro: Senac Rio, 2003. https://doi.org/10.1590/S0036-46652003000400017

WHO - World Helth Organization. Coronavirus disease 2019 (COVID-19). Situation Report - 72. Disponível em: https://www.who.int/docs/default-source/coronaviruse/situation-reports/20200401sitrep-72-covid-19.pdf?sfvrsn=3dd8971b 2. Acesso em: 30 abr 2020. 